\title{
THE CZECH ADAPTATION OF THE KLEIN ET AL.'S UNIDIMENSIONAL TARGET-NEUTRAL SCALE OF COMMITMENT
}

\section{Jakub Procházka, Anna Židlická, Hynek Cígler, Martin Vaculík, Howard J. Klein}

\section{Introduction}

Organizational commitment, along with job satisfaction, is one of the two most often researched work attitudes (Riketta, 2008). It is the center of attention because it affects key variables in organizations such as the wellbeing of employees (e.g. Sui, 2002), absence due to illness (e.g. Meyer \& Maltin, 2010), length of stay in an organization (e.g. Porter, Steers, Mowday, \& Boulian, 1974), turnover intentions (e.g. Vandenberghe \& Trembla, 2008), job satisfaction (Ulbegi \& Yalcin, 2016) and job performance (Riketta, 2002). Despite being a key construct in management, we are not aware of any published studies on a validated scale of organizational commitment in Czech. Such a situation is a limitation for researchers intending to examine organizational commitment, or at least monitor its influence when examining other variables. There is also a lack of a reliable scale which could be used when surveying employee attitudes within an organization. In this study, we address this gap and adapt an internationally used organizational commitment scale into Czech. The adapted scale will allow professionals and researchers to measure organizational commitment in Czech organizations reliably and to compare the commitment of Czech employees with foreign samples.

\section{Organizational Commitment}

Many definitions of organizational commitment have emerged over almost 60 years of commitment research. The first formal definition of commitment was proposed by Becker (1960), who wrote that 'commitments come into being when a person, by making a side bet, links extraneous interests with a consistent line of activity (p. 32).' Becker perceived 'side bets' as consequence of the person's participation in organizations. Other early influential definitions perceived commitment as 'bindings of the individual to behavioral acts that results when individuals attribute an attitude of commitment to themselves after engaging in behaviors that are volitional, explicit and irrevocable (Reichers, 1985 , p. 468)' or as 'the strength of an individual's identification with and involvement in a particular organization (Porter et al., 1974, p. 3).' In the early 1990s, Meyer and Allen (1991) introduced a three-component model of commitment which became the most widespread and dominant theory of organizational commitment (e.g. Bentein, Vandenberghe, Vandenberg, \& Stinglhamber, 2005). They defined commitment as a psychological state that has 'at least three separable components reflecting (a) a desire (affective commitment), (b) a need (continuance commitment) and (c) an obligation (normative commitment) to maintain employment in an organization (Meyer \& Allen, 1991, p. 61).' As with earlier definitions of commitment, Meyer and Allen's conceptualization of commitment was also criticized. Normative and continuance commitment are not attitudes towards organization but towards staying or leaving the organization (Solinger, van Olffen, \& Roe, 2008). The two theoretically separate dimensions normative and affective commitment - are in reality highly dependent, and they have only small incremental validity over each other (Bergman, 2006). The existence of a number of different definitions of organizational commitment and criticism of the dominant three-factor theory were examined by Klein, Molloy and Brinsfield (2012), who offered a new conceptualization of commitment. They defined commitment as a 'volitional psychological bond reflecting dedication to and responsibility for a particular target (p. 137).' In the conception of Klein, Molloy and Brinsfield (2012), commitment is a one-dimensional construct. The designation 
of commitment as a psychological bond implies it is a mental state which may change over time. Furthermore, the definition suggests it is a voluntarily bond, meaning that the person must decide to have a commitment regardless of what has led him/her to such a decision. A bond, defined in such a way, may relate to various "targets", i.e. not only to an organization but also, for example, to a team, to a superior at work, or to goals (Klein, Molloy, \& Brinsfield, 2012). The definition of commitment by Klein et al. (2012) has spread rapidly (see e.g. Solinger, Hofmans, Bal, \& Jansen, 2016; Deichman \& Stam, 2015; Walumbwa et al.'s, 2018). Considering how recently it came out, its prevalence and the thoroughness of its explanation (for more arguments see Klein, Cooper, Molloy, \& Swanson, 2014), we decided to base our work on Klein et al.'s. (2012) definition of organizational commitment as a psychological bond with an organization. This decision also influenced our choice of the organizational commitment scale for translating and adapting into Czech.

\subsection{Measurements of Organizational Commitment}

The most common tools for measuring organizational commitment are the 15-item unidimensional Organizational Commitment Questionnaire (OCQ, Mowday, Steers, \& Porter, 1979), the 18-item three-dimensional revised Three Component Model of Organizational Commitment (TCM, Meyer, \& Allen, 1991) and Klein et al.'s 4-item Unidimensional, TargetNeutral Measure of Commitment (KUT, Klein et al., 2014).

The OCQ is based on a definition of commitment as the strength on an individual's identification with and involvement in a particular organization (Porter et al., 1974). A factor analysis did not support its unidimensional structure (Angle \& Perry, 1981). Furthermore, Klein et al. (2014) questioned its content validity because of its overlap with job satisfaction, identification with an organization and turnover intention.

The TCM (Meyer \& Allen, 1993) scales measure the three commitment mindsets according to Meyer and Allen's definition (1991). The critique of this measure is based on the critique of the three-component model (see above). Furthermore, it is not possible to use the scale to measure commitment as a single construct as the continuance commitment scale does not correlate with the two other scales (Meyer et al., 2002). Moreover, the continuance commitment scale did not prove its unidimensionality and its two subfactors correlate differently with affective commitment (Solinger et al., 2008).

The KUT scale (Klein et al., 2014) measures commitment in accordance with the definition of commitment as a bond (according to Klein et al., 2012). It is the shortest of the three most widespread scales, so it is possible to use it in research that is not primary focused on commitment without bothering the respondents. The scale also showed good psychometric characteristics (Klein et al., 2014), has been used in many studies since 2014 (e.g. Colledani, Capozza, Falvo, \& Di Bernardo, 2018; Fabiny \& Lovaš, 2018; Mai, Ellis, Christian, \& Porter, 2016) and was soon translated into 10 languages (Klein, 2018). We chose to adapt the KUT scale into Czech because of its compliance with the definition of commitment as a bond, its psychometric qualities and its potential to become the dominant scale in organizational commitment research.

\subsection{Klein et al.'s Unidimensional Target- Neutral Scale of Commitment (KUT)}

The KUT scale of commitment is a self-report scale that consists of four items that are measured on either a 5 or 7-point scale ranging from 1 (not at all) to 5 or 7 (extremely) (Klein et al., 2014). Klein and his team (2014), along with other experts, deductively generated items that were consistent with the definition of commitment presented by Klein et al. (2012). They also included items from previous commitment scales that corresponded to that definition of commitment. These items were used in three pilot studies. Finally, the authors chose the items with the best psychometric characteristics (i.e. variance, factor loading, contribution to scale's internal consistency) that corresponded to the most important domains of commitment. The first item should generally describe the construct, the second concerns dedication, the third concerns volition and the fourth concerns responsibility for the target. Another group of experts verified the final scale as a measure of commitment.

Klein et al. (2014) used these four items in a validation study on 5 samples with a total 
sample size of 2,487 respondents. Because they constructed the scale as target neutral, they assessed the commitment to 8 various targets. 2,082 out of 2,487 respondents assessed their commitment to some organization (i.e. organization commitment). The organizational commitment scale fitted the data well (MLMV estimator, $\mathrm{X}^{2}(2)=3.26$ with $p>.05$, RMSEA $=.02$ with $\mathrm{Cl}_{90 \%}=[.00 ; .05], S R M R=.00$, $W R M R=.13$ ), was internally consistent (with Cronbach $\alpha>.86$ ) and the items loaded highly on a single commitment factor (std. factor loadings for items: KUT1 $=.97, \mathrm{KUT2}=.84$, KUT3 $=.96$, KUT4 $=.91$ ). To provide evidence about convergent validity, Klein et al. (2014) reported high positive correlations between organizational commitment measured by KUT and several related constructs such as job satisfaction $(r=.17, p<.05$ for Minnesota Satisfaction Questionnaire; $r=.57, p<.01$ for the satisfaction scale from the Michigan Organizational Assessment Questionnaire MOAQ), turnover intentions $(r=-.43, p<.01)$, extra-role behavior $(r=.28, p<.01)$, perceived performance (measured as subjective in-role effort, $r=.42, p<.05)$ and organizational identification $(r=.53, p<.01)$. Organizational commitment measured by KUT correlated strongly with other older measures of organizational commitment (Mayer's et al., 1993) TCM: $r=.69, p<.01$ for affective commitment scale, $r=.58, p<.01$ for normative commitment scale and $r=.04, p>.05$ for continuance commitment scale; Mowday's et al. (1979) OCQ: $r=.62, p<.01)$. The incremental validity of KUT over older commitment measures was assessed through a two-step regression analyses with KUT added in the second step. KUT explained significantly more variance over TCM in job satisfaction (measured by MOAS) $\left(\Delta R^{2}=.11, p<.01\right)$, organizational identification $\left(\Delta R^{2}=.19, p<.01\right)$ and turnover intentions $\left(\Delta R^{2}\right.$ $=.08, p<.01)$ but not in the extra-role behavior $\left(\Delta R^{2}=.00, p>.05\right)$.

Klein et al. (2014) provided evidence that a) they have created a scale of measuring commitment in accordance with its onedimensional target-neutral definition, b) that their organizational commitment scale has a high internal consistency, good convergent and concurrent validity, c) that it provides to a better explanation of related constructs to the previously published scales. We, therefore, consider the scale to be a suitable choice for adaptation to become the first validated scale of organizational commitment in Czech.

The main aim of the present study is to translate items of the KUT scale and to describe the whole adaptation and validation process, estimate the reliability of the scale, and provide evidence for the construct and convergent validity. In order to provide evidence on the reliability and validity of the Czech adaptation of the KUT scale, as with Klein et al. (2014), we tested its unidimensionality, internal consistency and convergent validity with respect to related constructs. To assess convergent validity, our constructs were similar to those of Klein et al. (2014) with regard to the availability of valid measuring instruments in Czech. The concurrent validity with another organizational commitment scale cannot be judged because there is no other validated scale of organizational commitment in Czech. Similarly, we cannot judge the incremental validity over other organizational commitment scales. However, we can judge incremental validity over job satisfaction, which is referred to as a construct that is close to organizational commitment. According to some authors, job satisfaction together with the organizational commitment form one higher-order factor called the "A-factor" (Newman, Joseph, \& Hulin, 2010). That is why we want to provide evidence that organizational commitment measured by the KUT scale helps to explain the variance in a related construct (i.e. job performance) over job satisfaction measured by an existing scale.

\section{Methods}

\subsection{Adaptation of Unidimensional, Target-Neutral Measure of Commitment}

When adapting the commitment scale to Czech, we used the original English Unidimensional, Target-Neutral Measure of Commitment (Klein et al., 2014). More specifically, we used the version focused on the commitment to an organization. The process of adaptation follows recommendations by Beaton, Bombardier, Guillemin and Ferraz (2000). It includes multiple translations to Czech, a translation back to English by a native speaker, a pilot study consisting of two rounds of cognitive interviews, a repeated evaluation of the translation by an expert, and a validation study. Two of the translations into Czech were 
carried out by the authors of this study. The third one was by someone who had not been introduced to the concept of organizational commitment. The authors compared their translations and synthetized a single Czech version which best resembled the content of the original English items. The Czech version was sent for translation to a native speaker from Great Britain, a long-term resident in the Czech Republic who speaks Czech very well. Without any knowledge of the original items, the native speaker translated the Czech items into English and then compared her translation with the content of the original items. The output of her work consisted of the translation back to English and of the notes regarding the deviations in the Czech translation. Based on these materials, we modified the content of the Czech items. The modified items were then described by the native speaker as identical to the original. Afterwards, these items were used in a pilot study in cognitive interviews using the method of "concurrent think alouds" (Tourangeau, Rips, \& Rasinski, 2000, p. 326327). The cognitive interviews were conducted with five respondents ( 3 of them female and 2 male, $M_{\text {age }}=32.4$ ). We did not encounter any problems with understanding the items during the cognitive interviews. Moreover, the respondents' thoughts were in line with the theory of organizational commitment. Later, we conducted another 8 cognitive interviews while using the method of "retrospective think alouds" (Jobe \& Mingay, 1989) (4 male and 4 female respondents, $M_{\text {age }}=27.3$ ). These interviews showed the items were comprehensible to the respondents. They could answer them when using the scale, and when answering, the respondents offered their thoughts in line with the commitment towards their organizations.

We then used this translation which had been verified through this process in our validation study. The four items of the scale are formulated as follows (original English items were taken from Klein et al., 2018):

KUT1. How committed are you to your organization? [Jak moc oddaný/á jste Vaší organizaci?]

KUT2. To what extent do you care about your organization? [Do jaké míry Vám na Vaší organizaci záleží?]

KUT3. How dedicated are you to your organization? [Jak moc se cítíte zanícenýlá pro práci ve Vaší organizaci?]
KUT4. To what extent have you chosen to be committed to your organization? [Jak moc jste rozhodnutýlá zůstat své organizaci věrnýlá?]

Respondents assessed the items on the five-point Likert scale ranging from 1 ('not at all' = 'vůbec ne') to 5 ('extremely' = 'extrémně moc').

\subsection{Other Instruments}

To assess convergent validity, we measured various constructs that are related to organizational commitment according to theories and previous research (see Introduction for brief references and Meyer and Allen (1997) for a detailed review of antecedents and consequences of organizational commitment). As we wanted to compare the Czech and original English scale, we chose the same constructs as Klein et al. (2014) in the original study. We used existing Czech scales of job satisfaction and job performance and we created new items for turnover intention and extra-role behavior.

\section{Job Satisfaction}

We measured job satisfaction using a 3-item General Satisfaction Scale from the Job Diagnostic Survey (Hackman \& Oldham, 1974). The scale has a 5-point response scale ranging from 1 (strongly disagree) to 5 (strongly agree). Hackman and Oldham (1974) reported high internal consistency of the original scale (Cronbach's $\alpha=.78$ ) and Kašpárková, Vaculík, Procházka and Schaufeli (2018) also reported high reliability of the Czech translation (Cronbach's $\alpha=.84$ ).

Similarly, in our analyses the scale reliability was good (McDonald's $\omega=.87$; Cronbach's $\alpha=.85$ ). All the items were (after reversing) slightly negatively skewed (skewness between -.70 to -.28). We did not report the result of confirmatory factory analysis as the model fit is always perfect with only three items.

\section{Perceived Job Performance}

We measured job performance using the 6 -item Czech scale of Perceived Job Performance (Vaculík, Vytásková, Vaculík, Procházka, \& Záliš, 2016) with a 5-point response scale ranging from 1 (strongly disagree) to 5 (strongly agree). All the items were (after reversing) negatively skewed (skewness between -1.22 to -.39). In our analysis, the internal consistency was good (McDonald's $\omega=.86$; Cronbach's 
$\alpha=.84)$. The scale was unidimensional and the ordinal confirmatory onefactor model fitted the data well, $X^{2}(9)=146.05, p<.001, T L I=0.954$, RMSEA $=0.138$ with $C l_{90 \%}=[0.119 ; 0.158]$, $S R M R=0.04$. Although the RMSEA seems to be low, it could be the effect of a small number of degrees of freedom (Kenny, Kaniskan, \& McCoach, 2014).
Extra-role Behavior and Turnover Intention Extra-role behavior (item: "At work I voluntarily do things which are not part of my duties.") and Turnover intention (item: "I have decided to leave this organization within the next 12 months.") were measured each by one item with a 5-point response scale ranging from 1 (strongly disagree) to 5 (strongly agree). The distribution of both items can be seen in Tab. 1 .

Tab. 1: Distribution of the other scales

\begin{tabular}{l|c|c|c|c|c|c|c|c} 
& $\mathbf{1}$ & $\mathbf{2}$ & $\mathbf{3}$ & $\mathbf{4}$ & $\mathbf{5}$ & $\boldsymbol{M}$ & $\mathbf{S D}$ & $\boldsymbol{M d n}$ \\
\hline Extra role behavior & 27 & 56 & 111 & 295 & 320 & 4.02 & 1.05 & 4 \\
\hline Turnover intention & 313 & 110 & 157 & 90 & 137 & 2.54 & 1.51 & 2 \\
\hline
\end{tabular}

Source: own

\subsection{Procedure and Sample}

The data were obtained through an electronic questionnaire as part of the research project focusing on the relationship between Czech leaders and followers. We addressed working adults from the Czech Republic via a paid Facebook advertisement and via a link posted in the Facebook groups and web forum discussions regarding work-related topics. We also shared the public Facebook event and sent direct e-mails to students of extramural study programs at Masaryk University. We described the purpose of our research to the potential respondents and we offered them a reward - in the form of discount coupons for the completion of the questionnaire. We also explained that by finishing the questionnaire they would be included in a prize draw for three six-month subscriptions of the "Respekt" magazine.

The questionnaire was submitted by 846 people. 12 of them did not fulfill the condition of working for at least two months at their current job. The respondents' answers might be influenced by their lack of experience and thus they were excluded from our analysis. We also excluded another 14 respondents from the analysis because they had not answered any of the questions on commitment. Additionally, we presumed some of the respondents would finish the questionnaire without reading the items only to get to the coupons. Therefore, we directly asked the respondents in the last part of the questionnaire if they read all items and whether they answered truthfully. Consequently, we excluded 4 respondents who admitted they had not read some of the items and yet answered them. We also excluded two respondents who did not answer the question about truthfulness. Finally, we excluded 3 respondents whose data matrix showed they kept using the same answer repetitively, meaning that they had filled out the questionnaire randomly.

The final sample size was $N=811$. All respondents were adults who had worked for at least 2 months in their current position under the same supervisor with a workload of at least 20 hours per week. $243(30 \%)$ respondents were men and 567 (70\%) women; one respondent did not state their sex. Only 6 respondents did not answer all of the KUT items; all of the questionnaires were answered completely by 795 participants. Apart from confirmatory factor analyses (list-wise; see below), we used pairwise case deletion.

The mean age was 31.1 years $(S D=8.27)$ with $M d n=29$ (quartiles $Q_{1}=25, Q_{3}=36$ ), with no difference between men and women, $t(512.4)=-.636, p=.525$. Men and women also did not differ in education level, $p(809)=.506$ (Mann-Whitney U test), work load, $p(776)=.782$ (Fischer exact test) or the number of past employers, $p(789)=.574$ (Mann-Whitney $\mathrm{U}$ test). However, men and women differed in the employment sector; there were more men in the private sector $(68 \%)$ than women $(60 \%)$, Fisher's exact test $p(746)=.039$, however the effect was small, Cramer's $V=.074$ (the 
private sector consisted of services, sales and production, the non-private sector was government or education).

Only 3 respondents (.4\%) had just an elementary-school education, 16 had secondary/apprenticeship (2\%), 310 had upper secondary or other higher education (38\%) and $481(59 \%)$ had a university degree. 595 (73\%) respondents worked full-time, $89(11 \%)$ parttime, $93(11.5 \%)$ of respondents had a service contract agreement (in Czech: Dohoda o provedení práce a Dohoda o pracovní činnosti) and 30 (4\%) had a different type of work. The number of employers in the past was left skewed with the mean $M=2.81(S D=1.87)$ and $M d n=2 ; 75 \%$ of respondents had 3 or fewer employers in the past.

\subsection{Analysis}

All the analyses were performed in the $R$ environment with several packages, in particular lavaan (Rosseel, 2012), semTools (semTools Contributors, 2016) and psych (Revelle, 2017). We used ordinal structural equation models (or confirmatory factor analyses) estimated on the polychoric correlation matrices with the robust WLSMV estimator. As this estimator cannot work with missing data and because the missingness was low, we used listwise deletion in structural models. In the scales with only one indicator (Extra role behavior and Turnover intention), we also used the latent variables. They were identified by setting their variance to 1 and the residual variance of their items to 0 .

We used McDonald's omega from these models as the reliability estimate (internal consistency). Its advantage is that it does not have an assumption of items tau-equivalence contrary to Cronbach's alpha (however, we reported both of them). Cronbach's alpha was estimated using a variance-covariance matrix (so-called raw alpha), the coefficient omega was computed using the model fitted to the polychoric correlation matrix. McDonald's omega can then be understood as the variance of unweighted sum of items explained by the latent trait (estimated without an assumption of interval items).

Model comparisons (e.g. in the invariance testing) were performed using the SatorraBentler solution (2010). We gradually fixed model parameters to the same values to test the scale invariance and compared each subsequent model with the previous one.
First, we fitted the unconstrained multigroup model (configural). Second, the loadings (metric invariance) and thresholds (scalar invariance) were constrained, which led to the same item characteristic curves for both groups. Third, the residual item variance were fixed (strict invariance) which secure the same measurement errors for both groups. Finally, we tested the average differences of both groups fixing the means of latent traits to zero. As a cut-off for difference fit indices, we used values proposed by Chen (2007) for small or unequal sample sizes, which can also be applied to ordinal CFA (Sass, Schmitt, \& Marsh, 2014): $\triangle C F I \leq-.005$ supplemented by $\triangle R M S E A \geq .010$ and $\triangle S R M R \geq .025$ (for metric invariance) or $\triangle S R M R \geq .005$ (for scalar or residual invariance) suggest the lack of invariance.

\section{Results}

\subsection{Content Validity and Reliability}

Frequencies and descriptives of the KUT items are in Tab. 2 together with the traditional classical test theory (CTT) statistics as Cronbach's alphas if the item was deleted and itemtotal correlation with correction of item overlap (Cureton, 1966). All the items positively contribute to the reliability, while removing any item always lead to the scale's lower reliability.

We then performed a unidimensional ordinal confirmatory factor analysis. The model fitted the data very well, $\mathrm{X}^{2}(2)=15.56, p<.001, T L I=.998$, RMSEA $=.092$ with $C l_{90 \%}=[.053 ; .137], S R M R$ $=.012, W R M R=.467$. Only the RMSEA was poor, but this can be attributed to the small number of degrees of freedom in the model (see Kenny, Kaniskan, \& McCoach, 2014). We can conclude that the KUT scale is unidimensional. All the standardized loadings were above .80 as the items were highly correlated, see Tab. 2 .

Internal consistency estimated using the CFA model was high, both McDonald's $\omega=.908$ and Cronbach's $\alpha=.908$. This indicates good reliability of the KUT scale.

\subsection{Convergent and Construct Validity}

We used other scales as measures of particular constructs to assess the convergent and construct validity of the KUT scale. For the convergent validity, Pearson's correlations of the observed mean score were used. The results are in Tab. 3. 
Tab. 2: Item descriptives, CTT item analysis and CFA loadings of the Czech KUT Scale

\begin{tabular}{|c|c|c|c|c|c|c|c|c|c|c|c|}
\hline & \multicolumn{6}{|c|}{ frequencies } & \multicolumn{2}{|c|}{ descriptives } & \multicolumn{2}{|c|}{ CTT item analysis } & \multirow{2}{*}{$\begin{array}{c}\text { CFA } \\
\text { loading }\end{array}$} \\
\hline & 1 & 2 & 3 & 4 & 5 & NA & $\mathbf{M}$ & SD & alpha & r.cor & \\
\hline KUT1 & 61 & 102 & 243 & 319 & 82 & 4 & 3.32 & 1.06 & .864 & .897 & .943 \\
\hline KUT2 & 59 & 101 & 178 & 375 & 97 & 1 & 3.43 & 1.08 & .865 & .894 & .948 \\
\hline KUT3 & 55 & 102 & 218 & 329 & 104 & 3 & 3.40 & 1.08 & .893 & .794 & .829 \\
\hline KUT4 & 116 & 150 & 215 & 242 & 88 & 0 & 3.04 & 1.22 & .905 & .768 & .811 \\
\hline
\end{tabular}

Source: own

Note: alpha - Cronbach alpha if item deleted; r.cor - item-total correlation corrected for item overlap, see Cureton (1966). CFA loading - standardized item loading in the pooled CFA model.

The series of ordinal structural equation models was used for the investigation of construct validity. In the first model, three latent factors were estimated with the appropriate items of KUT, job satisfaction (JS) and perceived job performance (JP) scales. This model fitted the data sufficiently, $\mathrm{X}^{2}(62)=560.63, \mathrm{p}<.001$, $T L I=.968, R M S E A=.101$ with $C l_{90 \%}=[.093 ; .108]$, $S R M R=.060, W R M R=1.824$.

As the WRMR and especially the RMSEA (in this case with a sufficient number of degrees of freedom) were poor, we explored the residual correlation matrix and modification indexes (M.I.). They suggested high residual correlations (above .10) between JS and KUT items, especially KUT4, and the highest M.I. was the loading of that item on the JS scale. We tried to allow this loading, which led to better model fit, $\Delta \mathrm{X}^{2}(1)=86.8, p<.001$, and the final model has significantly better fit indices, $X^{2}(61)=360.08$, $p<.001, T L I=.981, R M S E A=.079$ with $C l_{90 \%}$ $=[.071 ; .087], S R M R=.052, W R M R=1.428$. The standardized value of the crossloading was moderate, $\lambda_{\mathrm{s}}=.441$. The second highest M.I. was the residual correlation between this item (KUT4) and JS3 ("I frequently think of quitting this job”; in Czech: „Často přemýšlím o odchodu $z$ této práce."). The overlap of these items is not surprising, as both concern the readiness to stay at a current job or in the organization. Allowing for that residual correlation (and no crossloading) also improved the fit of the model $\left(\Delta X^{2}(1)=142.7, p<.001\right)$, and led to a good model fit $\left(X^{2}(61)=392.44, p<.001, T L I=.979\right.$, RMSEA = .083 with $\mathrm{Cl}_{90 \%}=[.075 ; .091], \mathrm{SRMR}$ $=.053, W R M R=1.510$ ), which was comparable to the model with crossloading. The value of the standardized residual correlation was very high $(r=-.727)$. As the items really ask about a similar thing, we decided to use this unconstrained model which allowed the residual correlation between these two items.

In the last step, we also included scales with only one indicator (Extra-role Behavior and Turnover Intention) into the model. The same residual correlation as above was allowed too. The model fitted data poorer, $X^{2}(81)=742.57$, $p<.001, T L I=.961, R M S E A=.102$ with $C_{90 \%}$ $=[.095 ; .108], S R M R=.060, W R M R=1.858$, and the difference of the latent trait correlations compared to the previous model was negligible, absolute values were lower than .003. The results from this model are in Tab. 3 .

The lower fit could be expected as some questions in the KUT and JS scales (especially the already mentioned KUT4 and JS3) concerned similar attitudes as the Turnover Intention (TI) item (JS3 concerned the intention to leave the job, KUT4 concerned the decision to stay committed to the organization, $\mathrm{TI}$ asked about the intention to leave the organization). We, therefore, allowed crossloadings between Turnover Intention and KUT4 and JS3. As these loadings can explain the residual correlation between items KUT4 and JS3, it was not allowed in the model and this model was not nested within the previous models (and cannot be compared directly). However, the model fit was better, $X^{2}(79)=352.79, p<.001, T L I=.983$, RMSEA $=.066$ with $\mathrm{Cl}_{90 \%}=$ [.059; .073], SRMR $=0.045$ and $\mathrm{WRMR}=1.222$. Unfortunately, as the differences in the loading definition changed the content validity of latent variables, the latent correlation of the three basic scales differed in this model from the previous models. The results are in Tab. 4. 


\begin{tabular}{|c|c|c|c|c|c|c|}
\hline \multirow[t]{2}{*}{ Tab. 3: } & \multicolumn{6}{|c|}{$\begin{array}{l}\text { Convergent (above the diagonal) and construct (below the diagonal) validity } \\
\text { of the KUT Scale }\end{array}$} \\
\hline & & KUT & JS & JP & ERB & TI \\
\hline KUT & & & .660 & .224 & .374 & -.598 \\
\hline \multicolumn{2}{|c|}{ Job Satisfaction (JS) } & .724 & & .163 & .227 & -.702 \\
\hline \multicolumn{2}{|c|}{ Perceived Job Performance (JP) } & .274 & .222 & & .270 & -.061 \\
\hline \multicolumn{2}{|c|}{ Extra Role Behavior (ERB) } & .438 & .290 & .332 & & -.175 \\
\hline \multicolumn{2}{|c|}{ Turnover Intention ( $\mathrm{TI}$ ) } & -.727 & -.831 & -.095 & -.210 & \\
\hline
\end{tabular}

Source: own

Note: Pearson correlation of observed score (item means) above diagonal, construct validity (latent variable correlation) below the diagonal. All the correlation are significant at $p<.001$ except correlation between ERB and JP ( $p=.122$ for construct/latent; $p=.081$ for convergent/manifest). In the SEM model, residual correlation between items KUT4 and JS3 $(r=-.714)$ was allowed.

\section{Tab. 4: Latent correlation of the model with crossloadings}

\begin{tabular}{l|c|c|c|c} 
& KUT & JS & JP & ERB \\
\hline JS & .671 & & & \\
\hline JP & .288 & .255 & & \\
\hline ERB & .452 & .312 & .332 & \\
\hline TI & -.563 & -.721 & -.063 & -.164 \\
\hline
\end{tabular}

Source: own

Note: Crossloadings of items KUT4 $(\beta=-.458)$ and JS3 $(\beta=.505)$ on the TI allowed. No other residual covariances allowed. Model fit: $\mathrm{X}^{2}(79)=352.79, p<.001, T L I=.983, R M S E A=.066$ with $C l_{90 \%}=[.059 ; .073], S R M R=0.045$ and WRMR $=1.222$.

\subsection{Incremental Validity of the Commitment to Job Performance over Job Satisfaction}

When investigating the incremental validity of the KUT scale to JP over JS, we modified the SEM model. The correlation between KUT and JS was unchanged, but we used regression paths instead of the correlations between KUT and JP, as well as between JS and JP. We investigated the model with latent variables (we left the residual correlation between JS3 and KUT4 items in this model), but we used the same model for the observed variables only (reversed item means).

The results were similar. The model with latent variables had an acceptable fit $\left(X^{2}(61)=392.44\right.$, $p<.001, T L I=.979$, RMSEA $=.083$ with $\mathrm{Cl}_{90 \%}=$ [.075; .091], $S R M R=.053$ and $W R M R=1.510$ ). Besides the high correlation between KUT and JS $(r=.721, p<.001)$, KUT predicted JP $(\beta=.239$, $p<.001)$, but JS did not $(\beta=.051, p=.396)$. On the observed scores, the correlation between KUT and JS was strong $(r=.660$, $p<.001)$, KUT predicted JP weakly $(\beta=.214$, $p<.001)$, and JS did not $(\beta=.022, p=.626)$.

KUT has an incremental validity over the JS to JP, but JS does not - it does not explain any additional variance of JP over KUT.

\subsection{Group Comparison and Factor Invariance of the KUT Scale}

The KUT scale was invariant between men and women, as we can see in Tab. 5. The model got significantly worse while testing the scalar and residual invariant model; but the difference in fit indices was negligible and the model with the same parameters for men and women was the best one. To be sure, if the lack of strict invariance led to different scale reliabilities, we compared McDonald's omegas for men 


\section{Tab. 5: Measurement invariance between men and women}

\begin{tabular}{|c|c|c|c|c|c|c|c|c|c|c|c|c|}
\hline & \multicolumn{6}{|c|}{ model } & \multicolumn{6}{|c|}{ model comparison } \\
\hline & df & $x^{2}$ & TLI & CFI & RMSEA & SRMR & $\Delta \mathrm{df}$ & $\Delta x^{2}$ & $\Delta \mathrm{TLI}$ & $\Delta \mathrm{CFI}$ & $\triangle$ RMSEA & $\Delta$ SRMR \\
\hline configural & 4 & 5.4 & .998 & .999 & .086 & .011 & & & & & & \\
\hline metric & 7 & 7.5 & .999 & .999 & .07 & .011 & 3 & 5.9 & .001 & .000 & -.016 & .000 \\
\hline scalar & 18 & 17.8 & .999 & .999 & .054 & .011 & 11 & $20.8^{*}$ & .001 & .000 & -.016 & .000 \\
\hline strict & 22 & 28.1 & .999 & .998 & .065 & .014 & 4 & $18.9^{+*+1}$ & .000 & .001 & .011 & .002 \\
\hline means & 23 & 28.1 & 1 & .999 & .033 & .014 & 1 & .000 & .001 & .002 & -.032 & .000 \\
\hline
\end{tabular}

Source: own

Note: ${ }^{*} p<.05 ;{ }^{* *} p<.01 ;{ }^{* * *} p<.001$. Configural invariance: no constrains. Metric invariance: loadings constrained to the same values in both groups. Scalar invariance: loadings and thresholds constrained. Strict invariance: loadings, thresholds and residual variances constrained. Means: loadings, thresholds, residual variances and latent means constrained.

and women based on a scalar invariant model. There were no meaningful differences in the internal consistency of the scale $\left(\omega_{\text {men }}=.857\right.$ and $\omega_{\text {women }}=.854$ ). We can conclude that the scale works in exactly the same way for both sexes and included no differences in the mean commitment trait.

The same result was found in the measurement invariance analysis by the work load if we compare people who work fulltime with people with parttime jobs (see Tab. 6). However, we can see a drop in the absolute fit indices (especially the RMSEA and chi-squared value) for the model with the same means, however, the difference test was not significant $(p=.054)$. The mean difference in the strict invariant model was small but significant (Cohen $d=.230, p=.005$ ).
People working parttime probably have slightly higher commitment compared to people who work fulltime.

The comparison of people working in the private sector with people working for NGOs or the state (predominantly teachers) had similar results (see Tab. 7), but we can see a significant worsening of the model in the scalar and means invariance, however, the difference fit indices were below the cut-offs. The only difference is a significant worsening of the chi-squared value and RMSEA in the means invariant model. The difference of latent mean from the strict model was significant $(p<.001)$, and people working for the private sector had moderately higher commitment compared to the NGOs and state employers (Cohen $d=.363, p<.001$ ).

Tab. 6: Measurement invariance by the work load (full vs. part time work)

\begin{tabular}{|c|c|c|c|c|c|c|c|c|c|c|c|c|}
\hline & \multicolumn{6}{|c|}{ model } & \multicolumn{6}{|c|}{ model comparison } \\
\hline & df & $x^{2}$ & TLI & CFI & RMSEA & SRMR & $\Delta \mathrm{df}$ & $\Delta \mathrm{x}^{2}$ & $\Delta \mathrm{TLI}$ & $\Delta \mathrm{CFI}$ & $\triangle$ RMSEA & $\Delta$ SRMR \\
\hline configural & 4 & 5.3 & .998 & .999 & .087 & .012 & & & & & & \\
\hline metric & 7 & 6.2 & .999 & .999 & .058 & .013 & 3 & 2.1 & .001 & .000 & -.030 & .000 \\
\hline scalar & 18 & 12.0 & 1.000 & 1.000 & .026 & .013 & 11 & 9.7 & .001 & .000 & -.031 & .000 \\
\hline strict & 22 & 14.1 & 1.000 & 1.000 & .021 & .013 & 4 & 2.9 & .000 & .000 & -.006 & .001 \\
\hline means & 23 & $59.3^{* * *}$ & .999 & .998 & .067 & .013 & 1 & 3.7 & -.001 & -.002 & .046 & .000 \\
\hline
\end{tabular}

Source: own

Note: ${ }^{*} p<.05 ;{ }^{* *} p<.01 ;{ }^{* * *} p<.001$. Configural invariance: no constrains. Metric invariance: loadings constrained to the same values in both groups. Scalar invariance: loadings and thresholds constrained. Strict invariance: loadings, thresholds and residual variances constrained. Means: loadings, thresholds, residual variances and latent means constrained. 
Tab. 7: Measurement invariance by the sector (private sector vs. NGOs and state)

\begin{tabular}{l|c|c|c|c|c|c|c|c|c|c|c|c} 
& \multicolumn{5}{|c|}{ model } & \multicolumn{6}{c}{ model comparison } \\
& $\mathrm{df}$ & $\mathrm{X}^{2}$ & $\mathrm{TLI}$ & $\mathrm{CFI}$ & RMSEA & SRMR & $\Delta$ df & $\Delta \mathrm{X}^{2}$ & $\Delta$ TLI & $\Delta$ CFI & $\begin{array}{c}\Delta \text { RM- } \\
\text { SEA }\end{array}$ & $\Delta$ SRMR \\
\hline configural & 4 & 6.2 & .997 & .999 & .095 & .012 & & & & & & \\
\hline metric & 7 & 7.9 & .999 & .999 & .069 & .013 & 3 & 3.7 & .001 & .000 & -.026 & .000 \\
\hline scalar & 18 & 21.3 & .999 & .998 & .064 & .013 & 11 & $28.4^{* *}$ & .000 & -.001 & -.004 & .001 \\
\hline strict & 22 & 26.3 & .999 & .998 & .062 & .016 & 4 & 8.6 & .000 & .000 & -.002 & .002 \\
\hline means & 23 & 127.5 & .996 & .993 & .114 & .015 & 1 & $8.0^{* *}$ & -.003 & -.005 & .052 & -.000 \\
\hline
\end{tabular}

Source: own

Note: ${ }^{*} p<.05 ;{ }^{* *} p<.01 ;{ }^{* * *} p<.001$. Configural invariance: no constrains. Metric invariance: loadings constrained to the same values in both groups. Scalar invariance: loadings and thresholds constrained. Strict invariance: loadings, thresholds and residual variances constrained. Means: loadings, thresholds, residual variances and latent means constrained.

\subsection{Other Findings}

We explored the relationship between age and education and the latent trait of KUT, JS and JP scales together with ERB and TI items. We used the same latent variable model, whose results are presented in Tab. 3 (residual correlation between items JS3 and KUT4, no other improvement). Age was transformed to the latent variable (the observed age had zero residual variance). Education was recoded to the binary variable: university degree vs. all the others and then used as a predictor of all the latent variables.

The model fitted the data $\left(X^{2}(101)=772.27, p<.001, T L I=.960, R M S E A\right.$ $=.094$ with $\mathrm{Cl}_{90 \%}=[.088 ; .100]$, SRMR $=.057$ and $W R M R=1.676)$ and the latent variable correlations remained unchanged (all the absolute values of their differences were smaller than .011). Education did not predict any other variable (all $p>.25$ ) except the age $(\beta=.192$, $p=.009$ ), which could be expected as university undergraduate students were also included in the sample. On the other hand, age correlated with most of the other variables (KUT: $r=.114$, $p=.002 ; \mathrm{JS}: r=.028, p=.460 ; \mathrm{JP}: r=.071$, $p=.067$; ERB: $r=.153, p<.001$; TI: $r=-.140$, $p<.001)$.

\section{Discussion}

This study introduces a Czech adaptation of Klein et al.'s Unidimensional Target-neutral scale of Commitment and provides evidence about the reliability and validity of the scale if the scale is used for measuring organizational commitment (i.e. the target is commitment to an organization). To secure content validity and equivalence with the original scale, two authors, experts in the field, chose the Czech version of the KUT items after reviewing three independent translations to Czech, a backtranslation to English, outputs form 13 cognitive interviews and after comparing the final Czech statements with commitment definition according to Klein et al. (2012). Moreover, the English native speaker, who also speaks Czech, confirmed that the Czech items have the same meaning as the English original.

Further evidence on validity and reliability was based on an analysis of the data obtained from a sample of 811 Czech working adults. The analysis showed that the Czech scale is internally consistent according to both McDonald's $\omega$ and Cronbach's a which indicated its high reliability. The confirmatory analysis provided evidence about the good factor validity of the scale; all four items loaded highly on the single commitment factor and the model fitted the data well. To assess convergent validity, we analyzed the relationship between organizational commitment measured by the Czech version of KUT and other constructs that are related to organizational commitment according to the theory and previous research. Organizational commitment measured by KUT was in a weak positive relationship with 
perceived own job performance (compare e.g. with Riketta, 2002), in a moderate positive relationship with extra-role behavior (compare e.g. with Tremblay, Cloutier, Simard, Chênevert, \& Vandenberghe, 2010), in a strong relationship with job satisfaction (compare e.g. with Ulbegi \& Yalcin, 2016) and in a strong negative relationship with turnover intention (compare e.g. with Vandenberghe \& Trembla, 2008).

The 5-factor model with commitment measured by KUT, job satisfaction, perceived job performance, extra-role behavior and turnover intention fitted the data well and all correlations of latent variables between commitment and other related constructs were lower than .75 which indicates good discriminant validity of the KUT scale. Commitment measured by the KUT scale also showed good incremental validity to job performance over the existing Czech scale of job satisfaction. The KUT scale was invariant across various groups. It had similar psychometric characteristics for men and women, for full-time and part-time workers and for employees in private sector and NGOs \& state institutions. The only difference is that when using the Czech KUT scale, fulltime employees seem to be slightly more committed than part-time employees, and that employees in the private sector seem to be moderately more committed than NGOs and state employees. However, this difference might not be attributed to the scale, but to the real difference in organizational commitment between particular populations.

The Czech adaptation of the KUT scale showed similar psychometric characteristics to the original English version (Klein et al., 2014). All items in both the Czech and English version have high factor loadings (above .80). The relationships between commitment measured by the KUT scale and other constructs in our study are also similar to those in the US study with the strongest relationship between organizational commitment and job satisfaction (.60 in the original study, resp. .66 in our study) and turnover intention (-.45 resp. -.60), moderate relationship with extrarole behavior (.28 resp. .37) and the weakest relationship between commitment and job performance (.18 resp. .22; commitment to the organizational goal was assessed in the original study). Small differences in the values of correlation coefficients of those relationships can be explained by different samples and by differences in scales that were used for measuring the related constructs in the Czech and US studies.

Unlike the original study (Klein et al., 2014), we report correlated residuals of the fourth item of the KUT scale (KUT4) and the question on the intention to leave. Similarly, we found correlated residuals of KUT4 and the third item of the General Job Satisfaction scale from the Job Diagnostic Survey (JS3, i.e. "I frequently think about quitting this job.", Hackman \& Oldham, 1974). The fourth item of the KUT scale (KUT4, i.e. "To what extent have you chosen to be committed to your organization") is the only item in the scale which asks about a conscious decision (i.e. "...have you chosen..."). As it asks about the decision to be committed (i.e. "věrný" in Czech), it may be perceived by some respondents to be the direct opposite of turnover intention. Again, JS3 concerns the decision to leave the job, which may also mean leaving the organization and not being committed. We think that this item describes the consequence of job satisfaction, not job satisfaction itself. However, it is part of a frequently used job satisfaction scale and is used as an indicator of job satisfaction. The closeness of the KUT4, JS3 and turnover intention might distort the correlations between organizational commitment, turnover intention and satisfaction when using the scores observed in the analyses. We strongly recommend using structural modeling in such cases and consider correlated residuals and possible cross-loadings in the model and in the interpretation of the results.

We found incremental validity of commitment measured by the Czech KUT scale to performance over job satisfaction. However, we did not find the opposite. Job satisfaction did not explain the significant amount of variance in performance over organizational commitment. This may lead to the question of whether there are two different constructs, or whether the commitment measured by the KUT also includes job satisfaction. We believe that the problem of incremental validity of satisfaction over commitment presented in this study can be attributed to the job satisfaction scale rather than the KUT scale. The satisfaction scale only contains three general items. As mentioned, one of them concerns turnover intention rather than satisfaction. The three-item scale from the Job 
Diagnostic Survey measures satisfaction very narrowly in comparison to e.g. the 20-item-long Minnesota Satisfaction Questionnaire (Weiss et al., 1967) which was used by Klein et al. (2014). This is maybe why satisfaction did not show incremental validity over related construct. Therefore, we recommend using a more complex measurement of job satisfaction when employing both organizational commitment and job satisfaction variables in a single study.

\subsection{Strengths and Limitations}

The scale was shown to be invariant across various groups. This allows for the use of the observed scores to compare the commitment of various groups and in various environments. However, we only considered three conditions (sex, full-time/part time, type of organization) in the analysis of invariance. Further research is needed to find more evidence of scale invariance between different groups.

One advantage of the study is the large sample size of 811 working adults, which allowed us to carry out the confirmatory factor analysis as well as test the scale of invariance across various groups and test the KUT scale within a complex structural model with five factors. However, we did not use a random sampling method and the sample did not represent the typical Czech working population. Women, younger respondents and respondents with university degrees were in the majority. We showed that age is related to organizational commitment measured by KUT scale; the older respondents were slightly more committed. Therefore, the sample was unbalanced in terms of at least one variable connected to commitment. As a result of this, we cannot recommend using the reported descriptive statistics of the organizational commitment variable (i.e. mean, SD, quartiles) as a background for Czech norms.

The original KUT scale was created as a target-neutral measure of commitment and Klein et al. (2014) reported evidence about its validity when measuring various targets. The Czech adaptation also allows for the alteration of the word "organization" for a different word that describes another target. However, we did not include different targets for our validation study and we cannot provide support for using this scale for measuring commitment towards teams or leaders, for example. Although we believe that the Czech KUT scale can measure different types of commitment, it will still need to be verified in further studies.

\subsection{Conclusion}

This study presented a contemporary, short and internationally used measure of commitment. It provided evidence on its internal consistency, content, factor, convergent, discriminant and incremental validity and showed its invariance across various groups. It offers a powerful tool for Czech research on commitment as well as for further research in which commitment should be monitored as a possible intervening variable. The measure can also be used for organizational surveys. It allows a comparison of the commitment in different parts of the organization and the assessment of the impact of the other variables on the employees' organizational commitment.

The study is based on thesis of Anna Zidlicka. The study was supported by the Czech Science Foundation under grant GA17-09797S and by Masaryk University under grants MUNI/A/1148/2018 and MUNI/A/1376/2018.

\section{References}

Angle, H. L., \& Perry, J. L. (1981). An empirical assessment of organizational commitment and organizational effectiveness. Administrative Science Quarterly, 1-14. http://dx.doi.org/10.2307/2392596.

Beaton, D. E., Bombardier, C., Guillemin, F., \& Ferraz, M. B. (2000). Guidelines for the process of cross-cultural adaptation of self-report measures. Spine, 25(24), 31863191 . http://dx.doi.org/10.1097/00007632200012150-00014.

Becker, H. S. (1960). Notes on the concept of commitment. American Journal of Sociology, 66(1), 32-40. http://dx.doi.org/10.1086/222820.

Bentein, K., Vandenberghe, C., Vandenberg, R., \& Stinglhamber, F. (2005). The role of change in the relationship between commitment and turnover: a latent growth modeling approach. Journal of Applied Psychology, 90(3), 468-482. http://dx.doi.org/10.1037/0021-9010.90.3.468.

Bergman, M. E. (2006). The relationship between affective and normative commitment: review and research agenda. Journal of Organizational Behavior, 27(5), 645-663. http://dx.doi.org/10.1002/job.372.

Chen, F. F. (2007). Sensitivity of Goodness 
of Fit Indexes to Lack of Measurement Invariance. Structural Equation Modeling: A Multidisciplinary Journal, 14(3), 464-504. https://doi.org/10.1080/10705510701301834.

Colledani, D., Capozza, D., Falvo, R., \& Di Bernardo, G. A. (2018). The Work-Related Basic Need Satisfaction Scale: An Italian Validation. Frontiers in Psychology, 9, 1-14. https://doi.org/10.3389/fpsyg.2018.01859.

Cureton, E. (1966). Corrected item-test correlations. Psychometrika, 31(1), 93-96. https://doi.org/10.1007/BF02289461.

Deichmann, D., \& Stam, D. (2015). Leveraging transformational and transactional leadership to cultivate the generation of organization-focused ideas. The Leadership Quarterly, 26(2), 204-219. https://doi. org/10.1016/j.leaqua.2014.10.004.

Fabiny, N., \& Lovaš, L. (2018). Goal commitment mediates the relationship between expected positive consequences of goal attainment and effort. Studia Psychologica, 60(2), 84-93. https://doi.org/10.21909/ sp.2018.02.754.

Hackman, J. R., \& Oldham, G. R. (1974). The Job Diagnostic Survey: An Instrument for the Diagnosis of Jobs and the Evaluation of Job Redesign Projects. New Haven, CT: Yale University.

Jobe, J. B., \& Mingay, D. J. (1989). Cognitive research improves questionnaires. American Journal of Public Health, 79(8), 1053-1055.

Kašpárková, L., Vaculík, M., Procházka, J., \& Schaufeli, W. B. (2018). Why resilient workers perform better: The roles of job satisfaction and work engagement. Journal of Workplace Behavioral Health, 33(1), 43-62. https://doi.org/ 10.1080/15555240.2018.1441719.

Kenny, D. A., Kaniskan, B., \& McCoach, D. B. (2014). The Performance of RMSEA in Models With Small Degrees of Freedom. Sociological Methods \& Research, 44(3), 486-507. http:// doi.org/10.1177/0049124114543236.

Klein, H. (2018). K.U.T. Commitment Measure. Columbus, $\mathrm{OH}$ : The Ohio State University. Retrieved from https://u.osu.edu/ commitmentmeasure/.

Klein, H. J., Cooper, J. T., Molloy, J. C., \& Swanson, J. A. (2014). The assessment of commitment: Advantages of a unidimensional, target-free approach. Journal of Applied Psychology, 99(2), 222. http://doi.org/10.1037/ a0034751.

Klein, H. J., Molloy, J. C., \& Brinsfield, C. T. (2012). Reconceptualizing workplace commitment to redress a stretched construct: Revisiting assumptions and removing confounds. Academy of Management Review, 37(1), 130151. https://doi.org/10.5465/amr.2010.0018.

Mai, K. M., Ellis, A. P., Christian, J. S., \& Porter, C. O. (2016). Examining the effects of turnover intentions on organizational citizenship behaviors and deviance behaviors: A psychological contract approach. Journal of Applied Psychology, 101(8), 1067-1081. https:// doi.org/10.1037/apl0000115.

Meyer, J. P., \& Allen, N. J. (1991). A three-component conceptualization of organizational commitment. Human Resource Management Review, 1(1), 61-89. https://doi. org/10.1016/1053-4822(91)90011-Z.

Meyer, J. P., \& Allen, N. J. (1997). Commitment in the Workplace: Theory, Research and Application. Thousand Oaks, CA: SAGE Publications. http://dx.doi. org/10.4135/9781452231556.

Meyer, J. P., \& Maltin, E. R. (2010). Employee commitment and well-being: A critical review, theoretical framework and research agenda. Journal of Vocational Behavior, 77(2), 323-337. http://doi.org/10.1016/j.jvb.2010.04.007.

Meyer, J. P., Stanley, D. J., Herscovitch, L., \& Topolnytsky, L. (2002). Affective, continuance and normative commitment to the organization: A Meta-analysis of antecedents, correlates, and consequences. Journal of Vocational Behavior, 61, 20-52. https://doi.org/10.1006/ jvbe.2001.1842.

Mowday, R. T., Steers, R. M., \& Porter, L. W. (1979). The measurement of organizational commitment. Journal of Vocational Behavior, 14(2), 224-247. https://doi.org/10.1016/00018791(79)90072-1.

Newman, D. A., Joseph, D. L., \& Hulin, C. L. (2010). Job attitudes and employee engagement: Considering the attitude "A-factor.". The Handbook of Employee Engagement: Perspectives, Issues, Research, 
and Practice, 43-61. https://doi.org/10.4337/97 81849806374.00010.

Porter, L. W., Steers, R. M., Mowday, R. T., \& Boulian, P. V. (1974). Organizational commitment, job satisfaction, and turnover among psychiatric technicians. Journal of Applied Psychology, 59(5), 603.

Příkazská, A. (2016). Překlad a adaptace metody $k$ měření závazku vưči organizaci [Translation and Adaptation of Organizational Commitment Questionnaire]. Bachelor thesis. Brno: Masaryk University.

Reichers, A. E. (1985). A Review and reconceptualization of organizational commitment. Academy of Management Review 10, 465-476. http://dx.doi.org/10.2307/258128.

Revelle, W. (2017). Procedures for Personality and Psychological Research. Evanston, IL: Northwestern University. Retrieved from https://cran.r-project.org/package=psych.

Riketta, M. (2002). Attitudinal organizational commitment and job performance: a metaanalysis. Journal of Organizational Behavior, 23(3), 257-266. http://doi.org/10.1002/job.141.

Riketta, M. (2008). The causal relation between job attitudes and performance: A meta-analysis of panel studies. Journal of Applied Psychology, 93(2), 472-481. https://doi. org/10.1037/0021-9010.93.2.472.

Rosseel, Y. (2012). Lavaan: An R package for structural equation modeling. Journal of Statistical Software, 48(2), 1-36.

Satorra, A., \& Bentler, P. M. (2010). Ensuring positiveness of the scaled difference chi-square test statistic. Psychometrika, 75(2), 243-248. https://doi.org/10.1007/s11336-009-9135-y.

Sass, D. A., Schmitt, T. A., \& Marsh, H. W. (2014). Evaluating model fit with ordered categorical data within a measurement invariance framework: A comparison of estimators. Structural Equation Modeling: A Multidisciplinary Journal, 21(2), 167-180. https://doi.org/10.1080/10705511.2014.882658.

semTools Contributors. (2016). Useful Tools for Structural Equation Modeling. R Package Version 0.4-11. Retrieved from http://cran.rproject.org/package=semTools.

Siu, O. (2002). Occupational stressors and well-being among Chinese employees:
The role of organisational commitment. Applied Psychology, 51(4), 527-544. http://doi. org/10.1111/1464-0597.t01-1-00106.

Solinger, O. N., Hofmans, J., Bal, P. M., \& Jansen, P. G. (2016). Bouncing back from psychological contract breach: How commitment recovers over time. Journal of Organizational Behavior, 37(4), 494-514. http://doi.org/10.1002/job.2047.

Solinger, O. N., Van Olffen, W., \& Roe, R. A. (2008). Beyond the three-component model of organizational commitment. Journal of Applied Psychology, 93(1), 70. http://doi. org/10.1037/0021-9010.93.1.70.

Tourangeau, R., Rips, L. J., \& Rasinski, K. (2000). The Psychology of Survey Response. Cambridge: Cambridge University Press. http:// dx.doi.org/10.1017/CBO9780511819322.

Tremblay, M., Cloutier, J., Simard, G., Chênevert, D., \& Vandenberghe, C. (2010). The role of HRM practices, procedural justice, organizational support and trust in organizational commitment and in-role and extra-role performance. The International Journal of Human Resource Management, 21(3), 405-433. https://doi.org/10.1080/09585190903549056.

Ulbegi, I. D., \& Yalcin, A. (2016). A MetaAnalytic Examination of the Relationship between Organizational Commitment and Job Satisfaction. Turk Psikoloji Dergisi, 31(77), 80-103. http://dx.doi. org/10.1348/096317909X478557.

Vaculík, M., Vytásková, J., Procházka, J., \& Záliš, L. (2016). Mindfulness, job satisfaction and job performance: Mutual relationships and moderation effect. In I. Simberova, F. Milichovský \& O. Žižlavský (Eds.), 21st International Scientific Conference Economics and Management 2016 - SMART and Efficient Economy: Preparation for the Future Innovative Economy (pp. 148-156), Brno: Brno University of Technology, Faculty of Business and Management.

Vandenberghe, C., \& Tremblay, M. (2008). The role of pay satisfaction and organizational commitment in turnover intentions: A twosample study. Journal of Business and Psychology, 22(3), 275-286. http://dx.doi. org/10.1007/s10869-008-9063-3. 
Walumbwa, F. O., Muchiri, M. K., Misati, E., Wu, C., \& Meiliani, M. (2018). Inspired to perform: A multilevel investigation of antecedents and consequences of thriving at work. Journal of Organizational Behavior, 39(3), 249-261. https://doi.org/10.1002/job.2216.

Weiss, D. J., Dawis, R. V., England, G. W., \& Lofquist, L. H. (1967). Manual for the Minnesota satisfaction questionnaire. In Minnesota Studies on Vocational Rehabilitation (Vol. 22). Minneapolis, MN: University of Minnesota Industrial Relations Center.
Ing. Mgr. Jakub Procházka, Ph.D. Masaryk University

Faculty of Economics and Administration Department of Corporate Economy Faculty of Social Studies Department of Psychology Czech Republic jak.prochazka@mail.muni.cz

Mgr. Anna Židlická Masaryk University Faculty of Social Studies Department of Psychology

Czech Republic 427160@mail.muni.cz

Mgr. Hynek Cígler, Ph.D. Masaryk University Faculty of Social Studies Institute for Research of Children, Youth and Family Faculty of Social Studies

Department of Psychology Czech Republic hynek.cigler@mail.muni.cz

doc. PhDr. Martin Vaculík, Ph.D. Masaryk University Faculty of Social Studies Department of Psychology Czech Republic vaculik@fss.muni.cz

Prof. Howard J. Klein, Ph.D. The Ohio State University Fisher College of Business Department of Management and Human Resources USA klein.12@fisher.osu.edu 


\title{
Abstract
}

\section{THE CZECH ADAPTATION OF THE KLEIN ET AL.'S UNIDIMENSIONAL TARGET-NEUTRAL SCALE OF COMMITMENT}

\author{
Jakub Procházka, Anna Židlická, Hynek Cígler, Martin Vaculík, Howard J. Klein
}

This study describes the process of translating, adapting and validating the Klein et al.'s Unidimensional Target-neutral Scale of Commitment (KUT) into Czech. The KUT scale is a selfreport scale that consists of four items. The scale was adapted using three independent translations into Czech, one back-translation into English by a native speaker, assessment by experts, and piloting in cognitive interviews with 13 respondents. The study also provides evidence on the scale's reliability and validity for measuring organizational commitment defined as a psychological bond with an organization. The analyses were based on data obtained from 811 Czech-speaking adults working for Czech organizations. Using ordinal structural equation models (SEM) estimated on the polychoric correlation matrices with the robust WLSMV estimator, the Czech adaptation of the KUT scale showed similar psychometric characteristics to the original English version. The Czech KUT scale is unidimensional and internally consistent. All items have high factor loadings. The scale is invariant across groups defined by gender, workload and the sector in which the organization operates. The convergent validity is supported by the fact that the organizational commitment measured by the Czech KUT scale relates positively to job satisfaction, self-rating of job performance, extra-role behaviour and negatively to turnover intention. The Czech KUT scale also proved incremental validity to job performance over job satisfaction measured by Job Descriptive Survey. Therefore, the scale is a valid instrument for measuring organizational commitment within the Czech-speaking population. It can be used for organizational surveys as well as for research within the organizations.

Keywords: Commitment, organizational commitment, scale adaptation, psychometric analysis.

JEL Classification: D63, J28, M12.

DOI: 10.15240/tul/001/2019-4-004. 